\title{
ARTESANOS Y SU POTENCIAL EMPRENDEDOR. VALLES CENTRALES DEL ESTADO DE OAXACA, 2018
}

\author{
CRAFTSMEN AND THEIR ENTREPRENEURIAL \\ POTENTIAL. CENTRAL VALLEYS OF THE STATE OF \\ OAXACA, 2018
}

Dr. Edmundo Mejía Sánchez a

Mtra. Josabeth Mendoza Juárez ${ }^{b}$

Lic. Laura Lizette Hernández Leyva ${ }^{c}$

\author{
a Benemérita Universidad Autónoma de Puebla \\ Facultad de Contaduría Pública, amenodan@hotmail.com

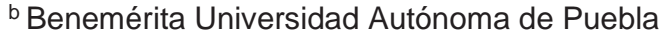 \\ Facultad de Contaduría Pública, josabeth2001@yahoo.com.mx \\ ${ }^{\mathrm{c}}$ Benemérita Universidad Autónoma de Puebla \\ Facultad de Contaduría Pública, lizhl_1011@hotmail.com
}

\section{RESUMEN}

Este trabajo consiste en el análisis de la situación en la que se encuentran los artesanos de Valles Centrales del estado de Oaxaca, derivado de la importancia que tiene está actividad para la diversidad cultural de la región, por lo que se expondrá cuál es la historia de la actividad artesanal y cómo ha evolucionado está técnica al pasar de los años en el progreso del hombre, también se mostrará cuál es la importancia de la elaboración de artesanías, partiendo de que México es un país rico en tradiciones, lenguas y costumbres, así mismo se analizan las condiciones socioeconómicas en que se encuentran y además, su potencial emprendedor. El objetivo general del trabajo consiste en indagar las características socioeconómicas, así como describir las condiciones de infraestructura y posicionamiento de sus productos en la región, Valles Centrales del estado de Oaxaca. La metodología empleada se sustenta en: investigación cualitativa a través de trabajo de gabinete y de campo en la región de Valles Centrales. Las técnicas de investigación que se emplearon son: entrevista, observación participante y aplicación de encuestas. Los resultados y limitaciones del estudio, a grandes rasgos: se obtuvo información detallada de la situación fiscal, económica, social y de infraestructura de una muestra representativa de artesanos. En cuanto a limitaciones, el trabajo de campo se concentró en una región acotada del estado de Oaxaca. Los principales hallazgos a los que se llegó son: conocer con detalle las condiciones de los artesanos, la cual es sistémicamente precaria y con grandes obstáculos para llevar a cabo pretensiones de emprendimiento de gran envergadura. 
PALABRAS CLAVE: Artesanía; Situación fiscal; Emprendimiento.

\begin{abstract}
This work consists of the analysis of the situation in which the Craftsmen of the Central Valleys of the State of Oaxaca are, derived from the importance of this activity for the cultural diversity of the region, so that the history of the craft activity and how this technique has evolved over the years in the progress of man, will also show what is the importance of the development of crafts, based on Mexico is a country rich in traditions, languages and customs, likewise it analyzes the socioeconomic conditions in which they are and also their entrepreneurial potential. The general objective of the work consists in analyzing the economic and social situation of the craftsmen and in demonstrating the conditions on their entrepreneurial potential. The methodology used is based on qualitative research through, cabinet and field work in the Central Valleys. The research techniques used were interviewing, participant observation, survey application. The results and limitations of the study, in broad strokes: detailed information was obtained on the fiscal, economic, social and infrastructure situation of a representative sample of craftsmen. In terms of limitations, the fieldwork was concentrated in a limited region of the state of Oaxaca. The main findings are to know in detail the conditions of the craftsmen, which is systemically precarious and with great obstacles to carry out pretensions of large-scale entrepreneurship.
\end{abstract}

KEYWORDS: Craftsmen; Fiscal situation; Entrepreneurship.

\title{
I. INTRODUCCIÓN
}

México es un país rico en diversidad cultural, a nivel internacional es considerado como un país con creatividad original, capaz de transformar toda su diversidad, sus tradiciones, su cultura en piezas artesanales únicas que definen a cada pueblo, a cada región, a cada etnia; en conjunto constituyen un mosaico cultural en el país.

La elaboración de artesanías es una actividad indispensable para la conservación de la diversidad cultural del país, sin embargo, se encuentra limitada por diversas condiciones. Este trabajo se realiza con ese propósito, revisar la situación de los artesanos en México a partir de una muestra representativa, con base en las siguientes categorías clave: artesanías, situación fiscal y emprendimiento.

\section{PLANTEAMIENTO DEL PROBLEMA}

El artesano en México se encuentra en una situación de vulnerabilidad estructural: la falta de estímulos, la desinformación sobre los regímenes fiscales, sumado con la carga tributaria que se puede tener por la venta de las artesanías que se elaboran. Ante está 
situación los artesanos han optado por trabajar sin la incorporación al sistema tributario, es decir, han optado por trabajar en la informalidad, teniendo esto como consecuencia que haya una menor fiscalización, que los artesanos, al no pertenecer al registro federal de contribuyentes, se encuentren con la imposibilidad de obtener apoyos económicos que otorga el gobierno para el desarrollo de la actividad artesanal. Luego, en consecuencia, no pueden emitir comprobantes fiscales por la venta de sus artesanías, impactando negativamente en sus ingresos al disminuir el volumen de sus ventas.

\section{OBJETIVOS}

\section{Objetivo general:}

Indagar las características socioeconómicas, así como describir las condiciones de infraestructura y posicionamiento de sus productos en la región, Valles Centrales del estado de Oaxaca.

\section{Objetivos específicos:}

- Analizar la situación de los artesanos, principalmente en cuanto a condición fiscal.

- Reflexionar sobre su potencial emprendedor a partir de ser parte de una situación formal fiscalmente hablando.

\section{MARCO TEÓRICO CONCEPTUAL}

En este proyecto de investigación se considera como artesanía, a un objeto creado por parte de un trabajador manual que se especializa en una técnica, y que trabaja solo o de manera conjunta con su familia (Etienne, 2009, p. 5).

La Ley Federal para el Fomento de la Microindustria y la Actividad Artesanal, vigente en 2018 en México, define que es una artesanía y que es un artesano en su artículo tercero fracción segunda y tercera, dando las siguientes definiciones:

Artesanía, actividad realizada manualmente en forma individual, familiar o comunitaria, que tiene por objeto transformar productos o substancias orgánicas e inorgánicas en artículos nuevos, donde la creatividad personal y la mano de obra constituyen factores predominantes que les imprimen características culturales, folklóricas o utilitarias, originarias de una región determinada, mediante la aplicación de técnicas, herramientas o procedimientos transmitidos generacionalmente.

Artesanos, son aquellas personas cuyas habilidades naturales o dominio técnico de un oficio, con capacidades innatas o conocimientos prácticos o teóricos, elaboran bienes u objetos de artesanía. 
La UNESCO en el Simposio UNESCO/CCI (Comité Consultivo Internacional) refiere que: los productos artesanales son aquellos producidos por artesanos, ya sea totalmente a mano, o con la ayuda de herramientas manuales o incluso de medios mecánicos, siempre que la contribución manual directa del artesano siga siendo el componente más importante del producto acabado (2007).

De las anteriores definiciones se puede entender como artesanía, aquella pieza obra del trabajo manual realizado por el artesano de manera individual, familiar o comunitaria, que se transmite de generación en generación y en el que se transforman recursos sostenibles procedentes de la naturaleza, así como materias inorgánicas objeto de transformación, en artículos nuevos, aportando creatividad, cultura y características de la región o comunidad a la que pertenecen, logrando hacer de cada pieza un trabajo único.

Así mismo, se entiende como artesano aquella persona con conocimientos teóricosprácticos adquiridos de sus ascendentes, capaz de transformar recursos de la naturaleza y materias inorgánicas, en artículos artesanales.

Con la revolución industrial y la aparición de la primera máquina el artesano comenzó a ser desplazado, debido a que los objetos que antes eran elaborados por ellos ahora eran fabricados por las máquinas, las cuales tenían una capacidad de producción mayor e inalcanzable por el artesano, adicionalmente a esto el valor de comercialización de los objetos producidos por las máquinas era menor al valor de comercialización de los elaborados por los artesanos, sin embargo la calidad de los artículos industrializados no competía ni puede competir con el acabado artístico y único de los productos artesanales (Baquero, 1950, p. 294).

El uso de la máquina relegó y demeritó el trabajo del artesano, pues ahora competía con un trabajo inexperto, cuya especialización debido a la división de trabajo se limitaba a la manipulación de una máquina o a un trabajo en específico dentro de la línea de producción. Con la llegada de la máquina surgieron algunas teorías que apoyaban la desaparición de la actividad artesanal (Baquero, 1950, p. 294).

Como podemos ver, en la actualidad, la actividad económica de los artesanos no ha desaparecido, pero si ha sido, económicamente, marginada. Respecto al emprendimiento, nos apoyamos en la propuesta de Alcaraz:

En el ámbito de los negocios, el emprendedor es un empresario; es el propietario de una empresa comercial con fines de lucro (...) para el [ámbito] académico, emprender es un vocablo que denota un perfil, un conjunto de características que hacen actuar a una persona de una manera determinada y le permite mostrar ciertas competencias para visualizar, definir y alcanzar objetivos (Alcaraz, 2013, p. 1).

Alcaraz (2013) apunta que algunas de las características que debe tener el 
emprendedor son:

- Capacidad para alcanzar metas.

- Iniciativa y responsabilidad.

- Realismo y autoconfianza.

- Tolerancia al cambio.

- $\quad$ Persistencia en la solución de problemas.

Además de estar de acuerdo con estas características, sin embargo, también se tiene la certeza de que desde el momento en que alguien, en este caso los artesanos, realizan sus actividades están emprendiendo, pero que la situación fiscal en la se encuentran también es un factor clave para el emprendimiento.

Por situación fiscal, se entiende que un contribuyente cumpla con sus obligaciones fiscales, es decir, ubicación y otros, con el ánimo de operar en el ámbito formal y legal.

\section{METODOLOGÍA, TÉCNICAS Y MATERIALES EMPLEADOS}

El enfoque utilizado en la presente investigación es mixto, pues se hace una combinación del cuantitativo y del cualitativo con base en la medición numérica y el análisis estadístico, para establecer patrones de comportamiento en la unidad de análisis.

El tipo de investigación es descriptiva debido a que busca especificar propiedades, características y rasgos importantes del fenómeno analizado. Se describen tendencias de un grupo o población, en este caso se busca definir cuáles son las características socioeconómicas, así como las actividades que realizan los artesanos respecto a su potencial emprendedor.

Para el desarrollo de este trabajo se parte del planteamiento del problema el cual consiste en la siguiente interrogante:

¿Cuál es la situación actual de los artesanos respecto a sus condiciones: económica, social y fiscal, que limiten o permitan su potencial emprendedor, ¿así como las condiciones de infraestructura y posicionamiento de sus productos en la región Valles Centrales del estado de Oaxaca?

Una vez establecido el planteamiento del problema, se define la siguiente hipótesis:

Al contar en México con un programa de apoyo que no sólo incorpore al artesano al sistema fiscal, sino que estimule, sistémicamente, las facilidades para comercializar sus productos dentro y fuera del país, se tendría una mayor fiscalización y se potenciaría el crecimiento personal y regional de las diferentes comunidades. 
La investigación de campo se realizó en la región Valles Centrales del estado de Oaxaca. De acuerdo con datos del INEGI, Oaxaca, es uno de los 10 principales estados dedicados a la elaboración de artesanías, con gran diversidad. Cuenta con 570 municipios, agrupados en 8 regiones, Sierra Norte, Sierra Sur, Istmo, Valles Centrales, Costa, Cañada, Mixteca y Papaloápam (INEGI, 2010).

Con base en el Directorio Estadístico Nacional de Unidades Económicas (DENUE) publicado por el INEGI, datos del censo económico 2014, en la región de Valles Centrales del estado de Oaxaca se tienen 10588 unidades económicas, dedicadas a la elaboración de artesanías, por lo que estas unidades económicas constituyen la población para el presente estudio.

El muestreo realizado, es un muestreo probabilístico debido a que todos los elementos de ésta tienen la misma posibilidad de ser elegidos para aplicar el instrumento de investigación. Se trata de una muestra aleatoria simple, es decir que, los elementos que constituyen la muestra serán escogidos al azar y tienen las mismas probabilidades de ser elegidos. El margen de error estimado para determinar la muestra es del $5 \%$, el nivel de confianza es del $90 \%$, y la variabilidad es del 50\%, teniendo un tamaño de muestra para esta población de 264 unidades.

La aplicación del instrumento a las 264 unidades determinadas en la muestra, se realiza en la Región Valles Centrales, en los municipios de Santa María Coyotepec y San Bartolo Coyotepec, dedicados a la elaboración de artesanías con barro negro; San Martín Tilcajete y San Antonio Arrazola, a la elaboración de Alebrijes; Santa María Atzompa, a la elaboración de artesanías con barro; San Pablo Villa de Mitla, a la elaboración de artesanías a base de telar; Teotitlán del Valle, a la elaboración de tapetes de lana y artesanías a base de telar.

\section{RESULTADOS}

Los instrumentos aplicados para el presente trabajo consisten en un cuestionario de 24 preguntas cerradas, las cuales se encuentran codificadas para facilitar la recopilación de la información, y tiene como objetivo conocer cuáles son las características socioeconómicas de los artesanos, así como recursos utilizados en la elaboración de estas y la situación fiscal en la que se encuentran estas personas (ver Anexo 1). Los hallazgos obtenidos son los siguientes:

El $80 \%$ de la población que se dedica a la elaboración de artesanías, son de sexo femenino y el $20 \%$ masculino, ver Figura 1 : 


\section{Sexo de las personas dedicadas a la actividad artesanal}

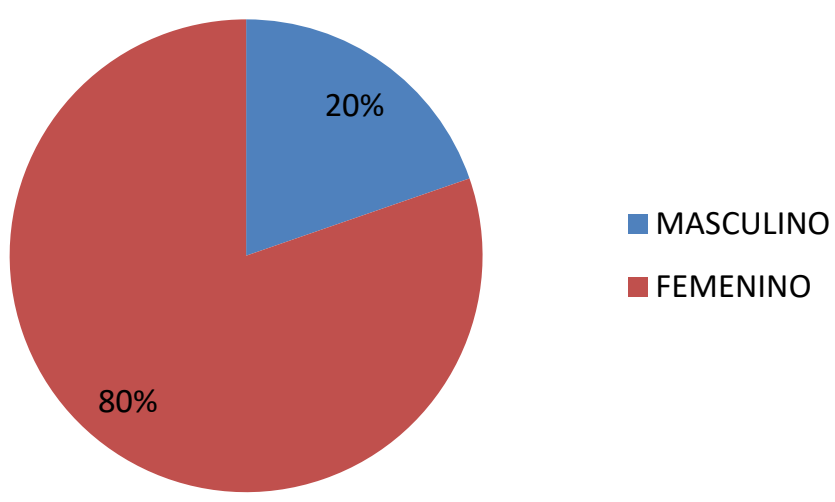

Figura 1. Sexo de las personas dedicadas a la actividad artesanal. Fuente: Elaboración propia con datos obtenidos de aplicación de encuesta.

En cuanto al rango de edad de los artesanos, se obtuvo como resultado que solo el $1 \%$ tienen hasta 18 años, el $5 \%$ de ellos oscila entre los 19 y 30 años, el 10\% tiene entre 31 a 40 años, el $19 \%$ se encuentra entre los 41 a 50 años, el $36 \%$ de los artesanos tiene de 51 a 60 años, es decir que la mayor parte de la población que se dedica a la actividad artesanal se encuentra en este rango de edad, el $29 \%$ de los artesanos tiene más de 60 años; la edad de las personas que se dedican a esta actividad se encuentra concentrado en un $84 \%$ en tres rangos, que en su conjunto se puede entender es de 41 años en adelante, (ver Figura 2).

\section{Edad de los Artesanos}

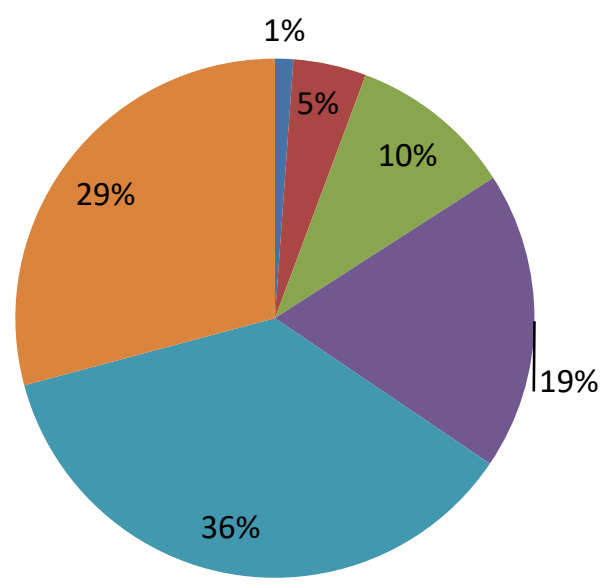

- Hasta 18 años

De 19 a 30 años

De 31 a 40 años

De 41 a 50 años

De 51 a 60 años

Más de 60 años

Figura 2. Edad de los Artesanos. Fuente: Elaboración propia con datos obtenidos de aplicación de encuesta.

Mejía, E., Mendoza, J. \& Hernández, L.L.

Artesanos y su potencial emprendedor. Valles centrales del Estado de Oaxaca 
Con referencia al estado civil de las personas dedicadas a la actividad artesanal, la información recopilada muestra que el $16 \%$ de las personas se encuentran solteros, el $65 \%$ se encuentra casado o en unión libre, el $2 \%$ están separadas de su pareja, el $1 \%$ se encuentran divorciados y otro $16 \%$ de los artesanos se encuentran viudos (ver Figura 3).

\title{
Estado Civil de los Artesanos
}

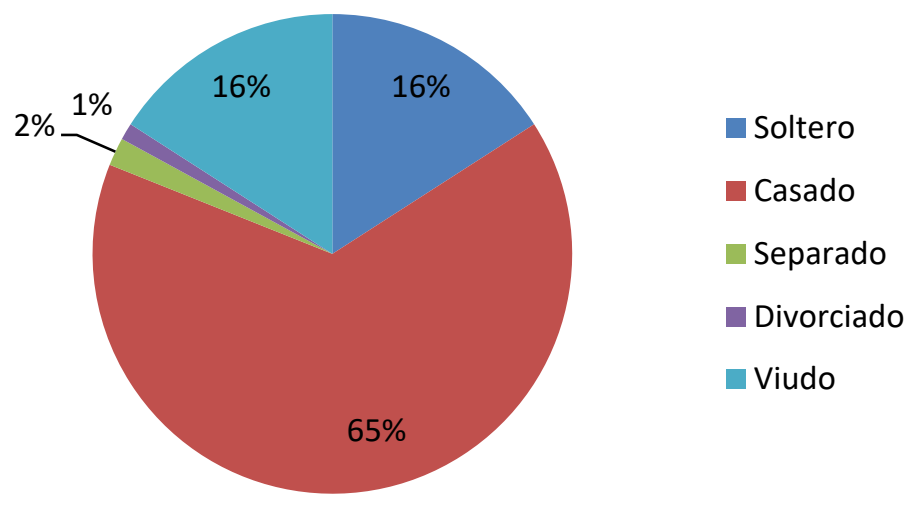

Figura 3. Estado Civil de los Artesanos. Fuente: Elaboración propia con datos obtenidos de aplicación de encuesta.

El grado escolar con el que cuentan los artesanos es en un $39 \%$ nivel primario o primaria trunca, 29\% secundaria, $8 \%$ cuentan con bachillerato, el 3\% con una licenciatura, el $0.4 \%$ tienen un posgrado, y el $21 \%$ de los artesanos no tienen estudios, en resumen, el $89 \%$ de la población dedicada a la actividad artesanal no cuenta con grado académico superior, sólo posee primaria o secundaria, ver Figura 4.

\section{Nivel de estudios de los Artesanos}

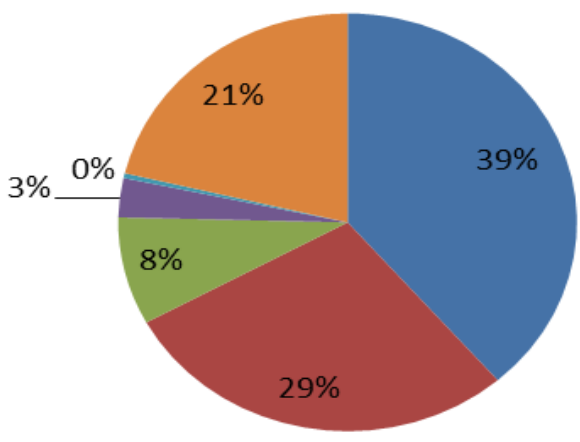

\author{
- Primaria \\ - Secundaria \\ Bachillerato/preparatoria \\ - Licenciatura \\ - Posgrado \\ Ninguno
}

Figura 4. Nivel de estudios de los Artesanos. Fuente: Elaboración propia con datos obtenidos de aplicación de encuesta.

Mejía, E., Mendoza, J. \& Hernández, L.L.

Artesanos y su potencial emprendedor. Valles centrales del Estado de Oaxaca 
En cuanto al nivel de ingreso que obtienen los artesanos los resultados obtenidos muestran que el $61 \%$ de estos tienen un ingreso mensual de hasta $\$ 2,191.20$ pesos, que equivalen a un salario mínimo elevado al mes, el $32 \%$ de los artesanos tiene un ingreso mensual de $\$ 2,191.21$ a $\$ 6,573.60$, es decir hasta tres salarios mínimos elevados al mes, el $5 \%$ de los artesanos obtiene un ingreso mensual en un rango de $\$ 6,573.61$ a $\$ 10,956.00$, es decir un rango de un centavo más de 3 veces el salario mínimo elevado al mes hasta 5 veces el salario mínimo elevado al mes, y solo un $2 \%$ de los artesanos tiene un ingreso que va de un centavo más de 7 salarios mínimos elevado al mes hasta $\$ 19,720.80$ que equivale a 9 veces el salario mínimo elevado al mes. Ver figura 5.

\section{Ingreso mensual de Artesanos}

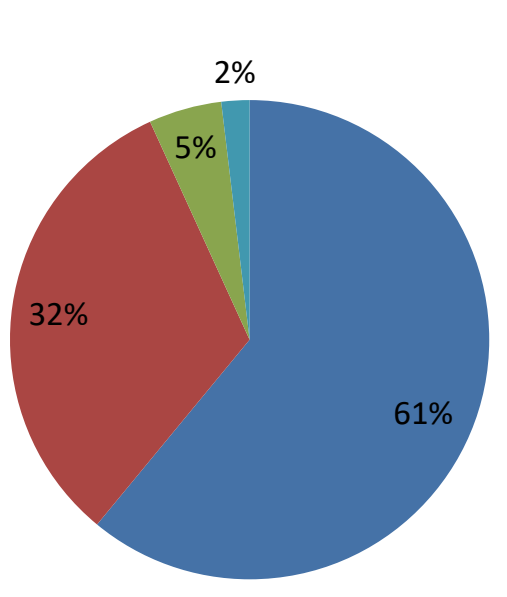

- Hasta $\$ 2,191.20$

De $\$ 2,191.21 \mathrm{a}$

$\$ 6573.60$

De $\$ 6573.61 \mathrm{a}$

$\$ 10,956.00$

De $\$ 10,956.00$ a

$\$ 15,338.40$

De $\$ 15,338.41$ a

$\$ 19,720.80$

Más de $\$ 19,720.80$

Figura 5. Ingreso mensual de Artesanos. Fuente: Elaboración propia con datos obtenidos de aplicación de encuesta.

En cuanto a la fuente de ingresos, el $69 \%$ de los artesanos manifestó que su fuente de ingresos es únicamente la elaboración y venta de artesanías, el $22 \%$ declaró como fuente de ingresos la compra y venta de artesanías, el 9\% expresó tener su fuente de ingresos de la elaboración, venta de artesanías y otra actividad que no tiene que ver con las artesanías, el $0.4 \%$ manifestó tener su fuente de ingresos de la compra, venta de artesanías y otra actividad no relacionada con las artesanías, ver Figura 6. 


\section{Fuente de Ingreso de los Artesanos}
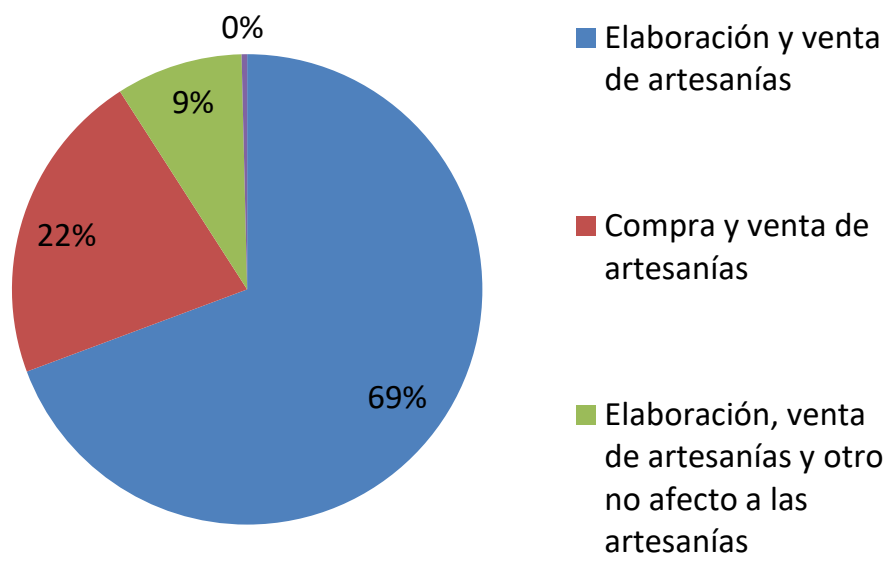

Figura 6. Fuente de Ingreso de los Artesanos. Fuente: Elaboración propia con datos obtenidos de aplicación de encuesta.

De las personas que tienen como única fuente de ingresos la elaboración y venta de artesanías o la elaboración, venta de artesanías y otra actividad no relacionada con las artesanías el $73 \%$ de los artesanos contesto que, si cuentan con personas que les ayudan en la elaboración de las artesanías, mientras que el $27 \%$ de los artesanos no tienen trabajadores. Ver Figura 7.

\section{Artesanos con ayuda para elaborar artesanías}

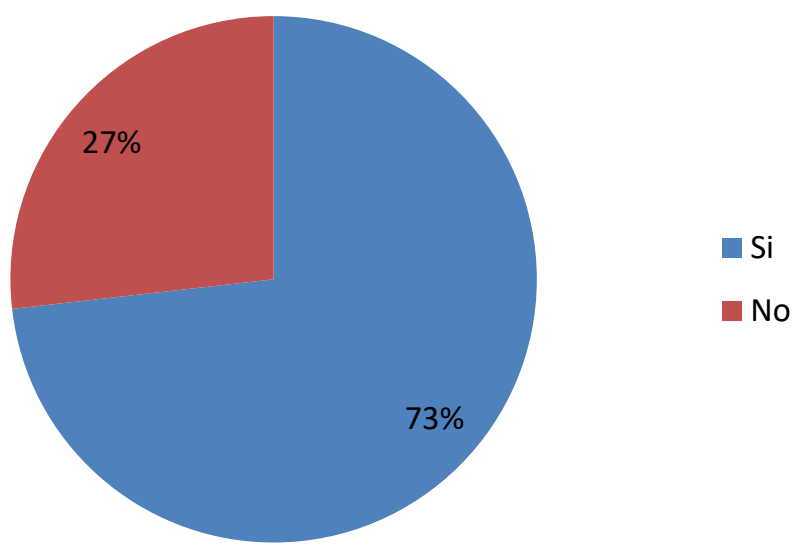

Figura 7. Artesanos con ayuda para elaborar artesanías. Fuente: Elaboración propia con datos obtenidos de aplicación de encuesta. 
De los artesanos que contestaron si contar con alguna persona que les ayude a elaborar sus artesanías el $76 \%$ afirmo recibir ayuda de sus familiares, es decir se trata de talleres artesanales familiares, y el $24 \%$ de los artesanos cuentan con trabajadores ajenos a la familia. Ver Figura 8.

\section{Personal que ayuda a los Artesanos}

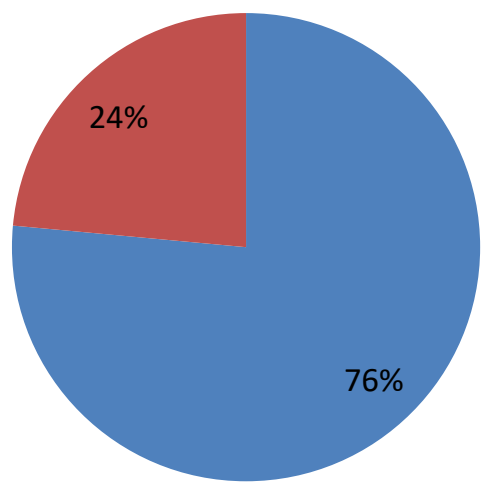

Familiares

Trabajadores (no familiares)

Figura 8. Personal que ayuda a los Artesanos. Fuente: Elaboración propia con datos obtenidos de aplicación de encuesta

De los artesanos que cuentan con personas que le ayudan a la elaboración de sus artesanías, sin importar si son familiares o ajenos a la familia, el $61 \%$ de los artesanos retribuyen económicamente a las personas que les ayudan, y el 39\% no retribuye económicamente a las personas que les ayudan con la elaboración de las artesanías, pues argumentaron que al tratarse de un taller familiar, el ingreso por la venta de artesanías es para la manutención de toda la familia y todos deben trabajar en su elaboración. Ver Figura 9.

\section{Artesanos que retribuyen económicamente a sus ayudantes}

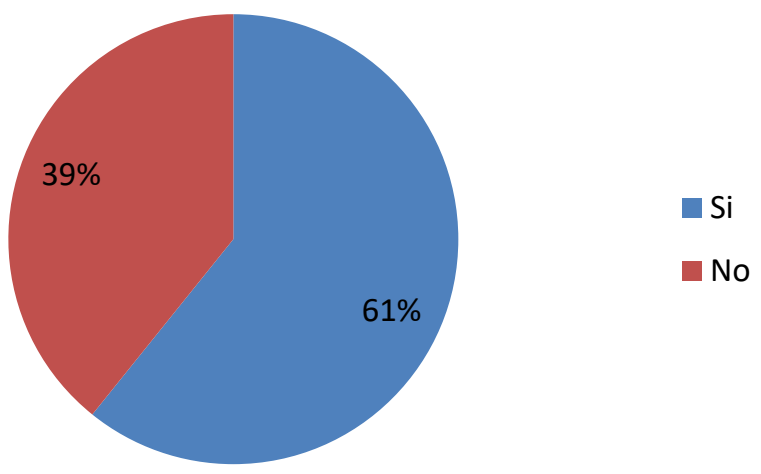

Figura 9. Artesanos que retribuyen económicamente a sus ayudantes. Fuente: Elaboración propia con datos obtenidos de aplicación de encuesta. 
De las personas que realmente tiene su fuente de ingreso de la elaboración y venta de artesanías, el 55\% obtienen los recursos para la elaboración de estas de proveedores, quienes les abastecen de hilos, madera, pinturas, y algunos recursos que los artesanos no pueden obtener de la naturaleza; el $45 \%$ de los artesanos obtiene sus insumos para la elaboración de artesanías. Ver Figura 10.

\section{Origen de los recursos para la elaboración de artesanías}

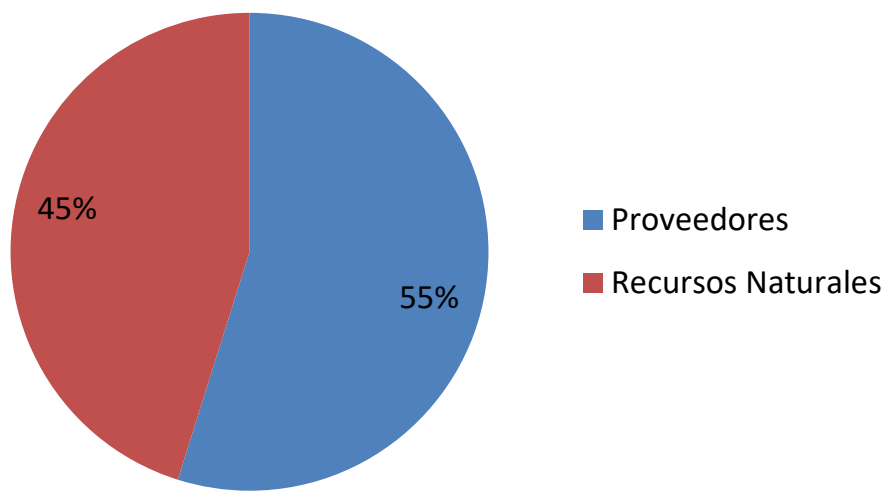

Figura 10. Origen de los recursos para la elaboración de artesanías. Fuente: Elaboración propia con datos obtenidos de aplicación de encuesta

Debido a la diversidad de artesanías que existen, a los diferentes recursos que se utilizan para su elaboración, a los detalles que cada artesano aporta en su producción, el tiempo que los artesanos tardan en elaborar una pieza depende de la misma; el 72\% de los artesanos afirmó tardar hasta 5 días en elaborar una pieza, el $17 \%$ es de 6 a 10 días, el 3\% de los artesanos tardan de 11 a 15 días en elaborarla, el $4 \%$ de 16 a 20 días y otro $4 \%$ tarda más de 21 días en elaborar una pieza (ver gráfica 11), este tiempo considera desde la preparación de la materia prima, hasta que el producto está terminado para su venta. 


\section{Tiempo de elaboración de una artesanía}

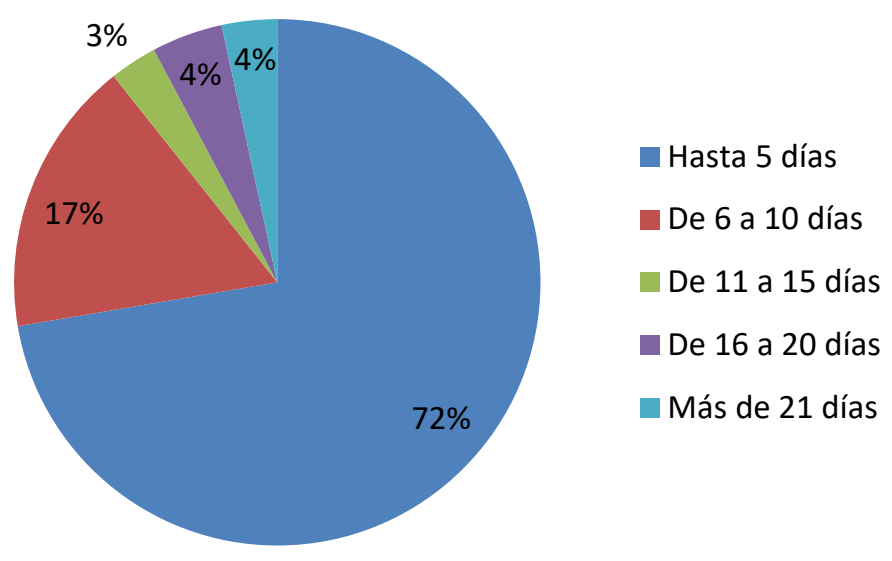

Figura 11. Tiempo de elaboración de una artesanía. Fuente: Elaboración propia con datos obtenidos de aplicación de encuesta.

Del total de artesanos que fueron encuestados el $41 \%$ afirmó pertenecer a un grupo de artesanos y el 59\% no pertenece a ninguna agrupación de artesanos. Ver Figura 12.

\section{Artesanos incorporados a grupo de artesanos}

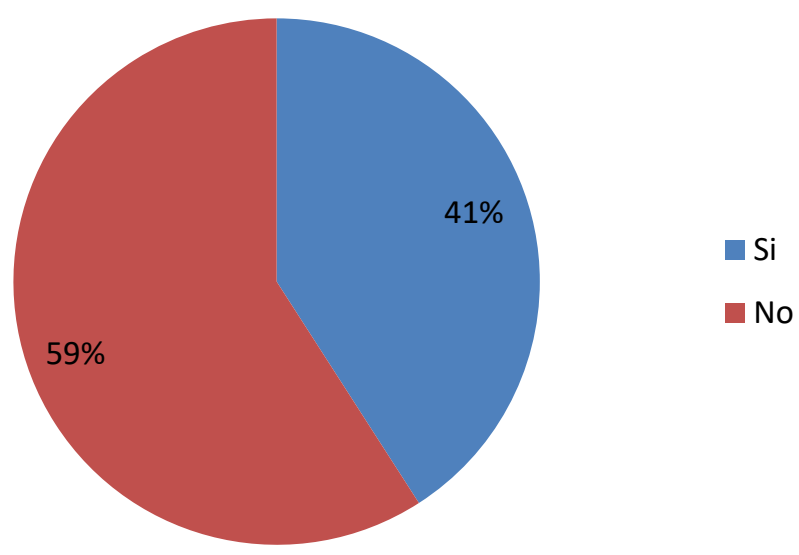

Figura 12. Artesanos incorporados a grupo de artesanos. Fuente: Elaboración propia con datos obtenidos de aplicación de encuesta

Del total de las personas encuestadas y dedicadas a la actividad artesanal el $46 \%$ se encuentran inscritas en el registro federal de contribuyentes, y el $54 \%$ de estas personas no se encuentran inscritas. Ver Figura 13. 


\section{Artesanos inscritos en el RFC}

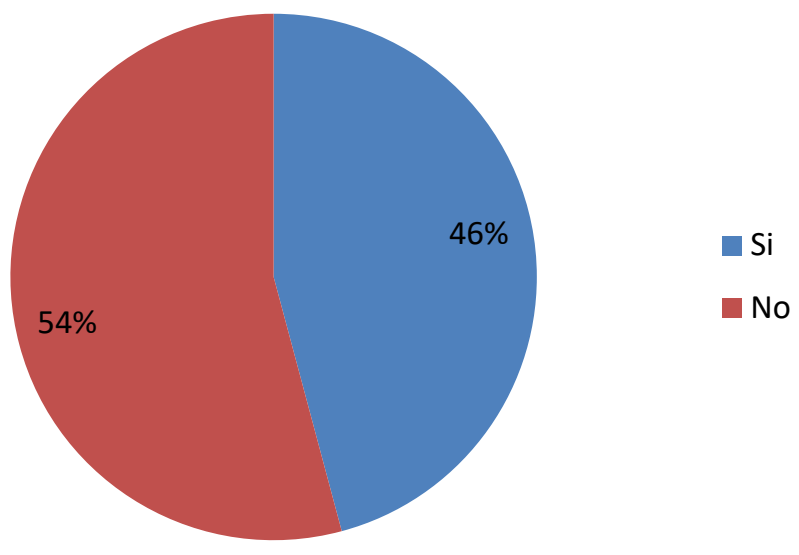

Figura 13. Artesanos inscritos en el RFC. Fuente: Elaboración propia con datos obtenidos de aplicación de encuesta

De los artesanos que no se encuentran inscritos en el RFC, el $48 \%$ de ellos comentó no haberse inscrito porque desconoce el procedimiento, así como las obligaciones, es decir no se encuentran en el RFC por falta de información, el $27 \%$ no se encuentra inscrito por falta de interés, es decir no les interesa o no quieren pagar impuestos, y el $25 \%$ dio una respuesta diferente a las anteriores, siendo ésta en todos los casos la insuficiencia de ingresos, es decir los ingresos que obtienen son mínimos o en algunos casos nulos por lo que no tienen las posibilidades de pagar impuestos y por lo mismo no se dan de alta en el RFC. Ver Figura 14.

\section{Razón por la que los artesanos no se inscriben al RFC}

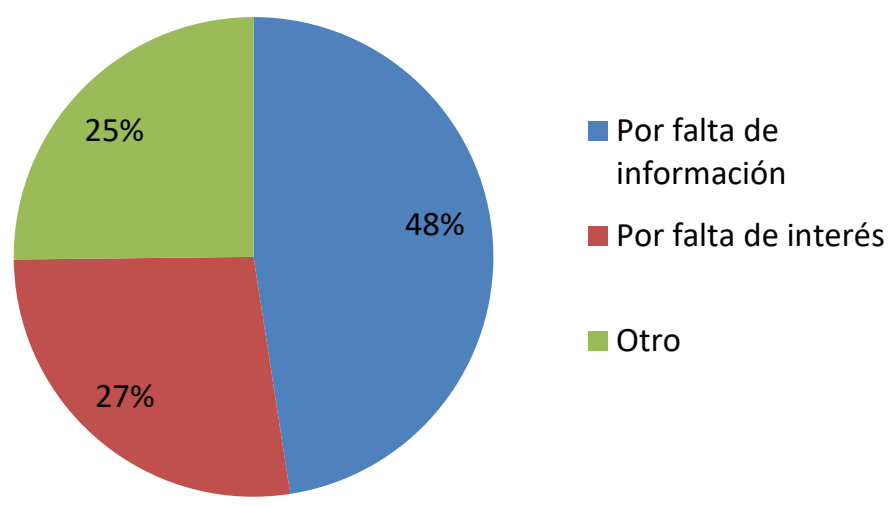

Figura 14. Razón por la que los artesanos no se inscriben al RFC. Fuente: Elaboración propia con datos obtenidos de aplicación de encuesta 
De los artesanos que se encuentran inscritos en el RFC, el $42 \%$ se inscribió para poder emitir facturas a sus clientes, el $12 \%$ porque fue requisito para tener acceso a algún apoyo económico, el $41 \%$ por que tuvieron alguna visita por el SAT o Secretaría de Finanzas, a través de alguna visita realizada por inspectores, el $5 \%$ se dio de alta por otra razón, como la de obtener el apoyo de una terminal bancaria. Ver Figura 15.

\section{Razón por la cual los artesanos se inscribieron al RFC}
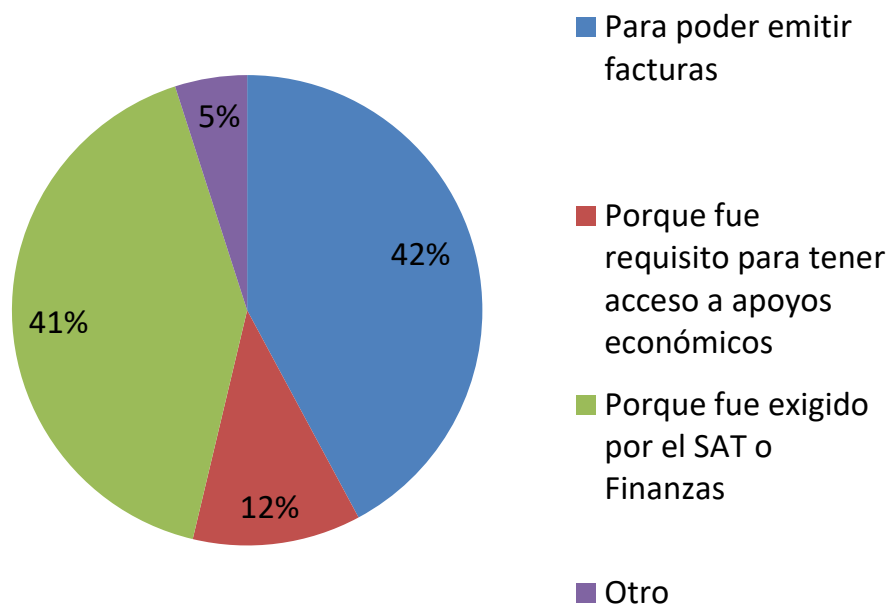

Otro

Figura 15. Razón por la cual los artesanos se inscribieron al RFC. Fuente: Elaboración propia con datos obtenidos de aplicación de encuesta.

De los artesanos inscritos en el RFC, el 96\% afirmó estar tributando bajo el régimen de pequeños contribuyentes, ahora régimen de incorporación fiscal, el $1 \%$ se encuentra inscrito bajo el régimen de actividades empresariales y profesionales, y el $2 \%$ en otro. En todos los casos se aprecia desconocimiento del régimen en que se encuentran inscritos. Ver Figura 16.

\section{Régimen bajo el que tributan los artesanos}
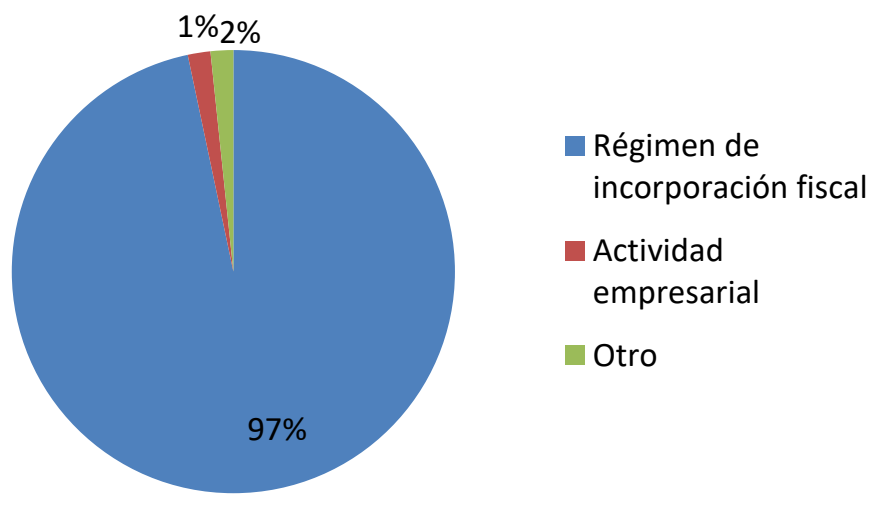

Figura 16. Régimen bajo el que tributan los artesanos. Fuente: Elaboración propia con datos obtenidos de aplicación de encuesta. 
De los artesanos inscritos en el RFC el $62 \%$ afirmó conocer cuáles son sus obligaciones fiscales y el $38 \%$ contestó que desconoce cuáles son sus obligaciones fiscales, esta información se muestra en la Figura 17.

\section{Artesanos que conocen sus obligaciones fiscales}

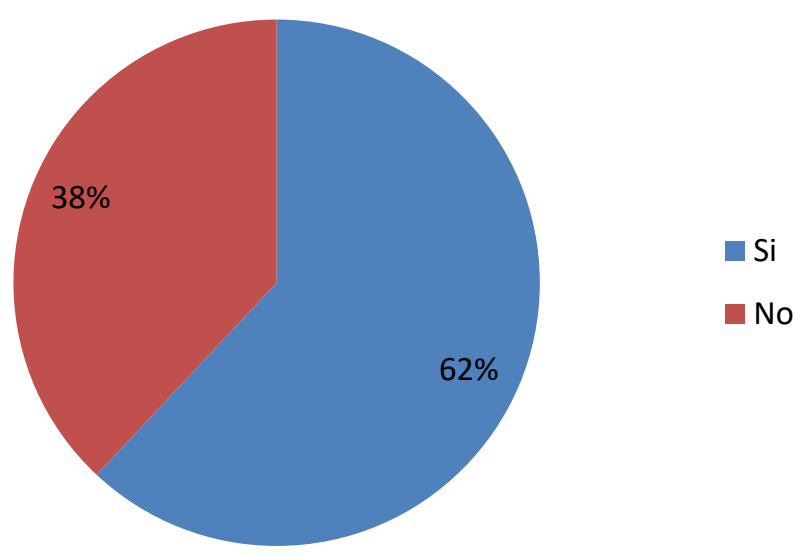

Figura 17. Artesanos que conocen sus obligaciones fiscales. Fuente: Elaboración propia con datos obtenidos de aplicación de encuesta.

De los artesanos que se encuentran inscritos en el RFC, el $64 \%$ cumple con sus obligaciones fiscales, como lo es el pago de impuestos, mientras que el $36 \%$ no cumple con sus obligaciones fiscales. Ver Figura 18.

\section{Artesanos que pagan impuestos}

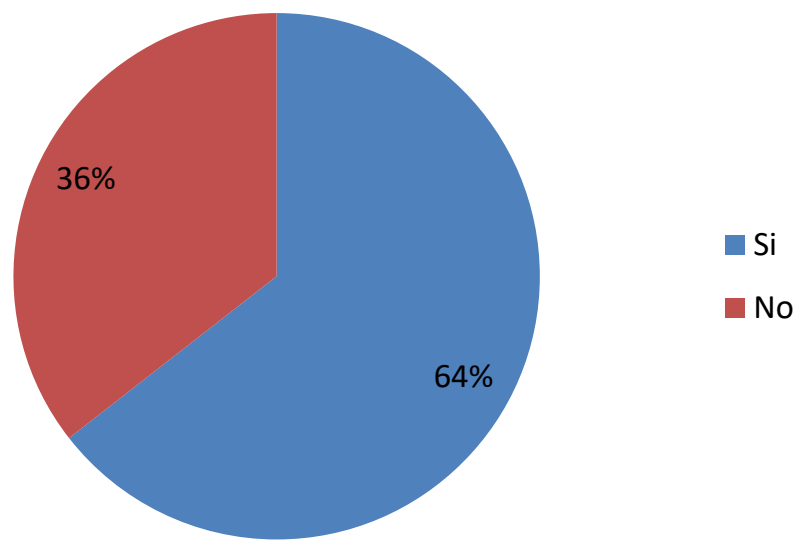

Figura 18. Artesanos que pagan impuestos. Fuente: Elaboración propia con datos obtenidos de aplicación de encuesta. 
Los artesanos que cumplen con sus obligaciones fiscales, principalmente con el pago de sus impuestos, informaron que los impuestos que pagan son ISR, IVA y otro, siendo nula la respuesta al pago del IMSS, el $64 \%$ de los artesanos paga ISR, el $22 \%$ paga IVA, de este $22 \%$ el $96 \%$ también paga ISR ya incluido en el $64 \%$ anteriormente expuesto, y el $14 \%$ respondió con otro, siendo aclaración a esta respuesta el pago de una cuota fija (que corresponde al régimen de pequeños contribuyentes ya extinto) o el pago de derecho de piso. Ver Figura 19.

Impuestos que pagan los artesanos

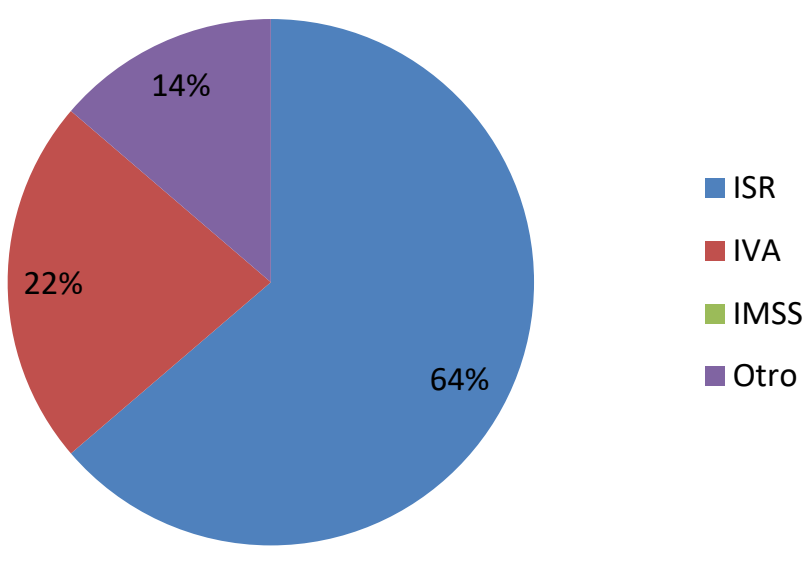

Figura 19. Impuestos que pagan los artesanos. Fuente: Elaboración propia con datos obtenidos de aplicación de encuesta.

De los artesanos que, aun estando inscritos en el RFC, no cumplen con el pago de impuestos el $2 \%$ afirma que no paga impuestos por que no le interesa cumplir con esa obligación, el $82 \%$ comentó que no paga impuestos por falta de conocimientos e información, $16 \%$ respondió que no paga impuestos por falta de recursos, es decir que sus ingresos son muy pocos y no le alcanza para cumplir con el pago de impuestos. Ver Figura 20. 


\section{Razón por la que los artesanos no pagan impuestos}

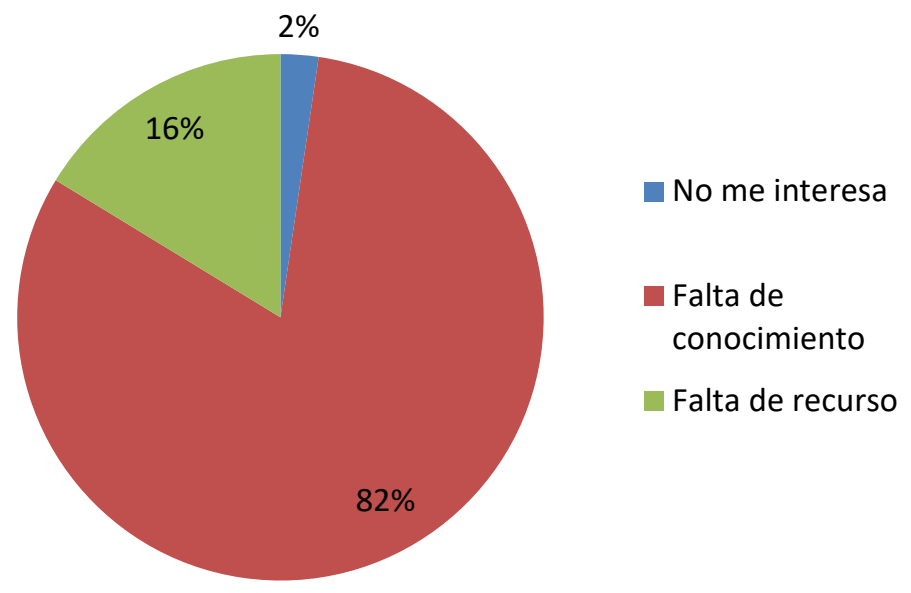

Figura 20. Razón por la que los artesanos no pagan impuestos. Fuente: Elaboración propia con datos obtenidos de aplicación de encuesta.

Se preguntó a los artesanos sobre los apoyos económicos que otorga el gobierno para el desarrollo y fomento de la actividad artesanal, y el 33\% informó que, si conoce o ha escuchado sobre estos apoyos, mientras que el 67\% los desconoce. Ver Figura 21.

\section{Artesanos que conocen sobre apoyos de gobierno}

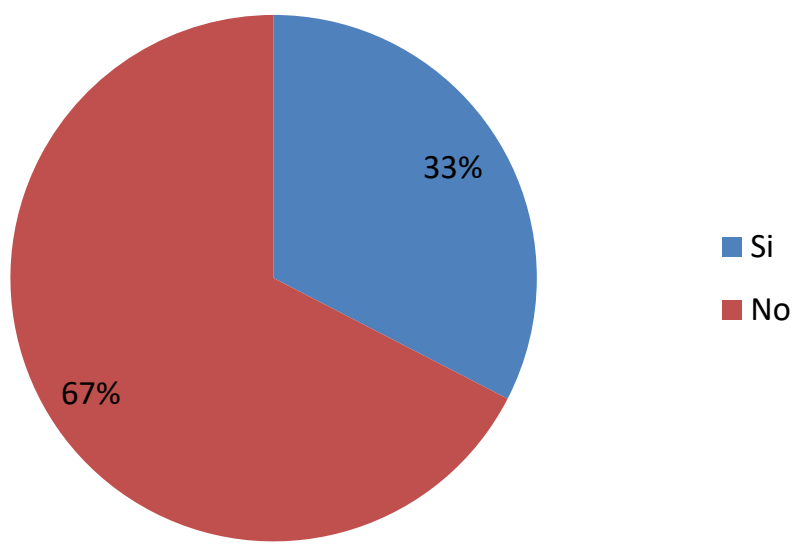

Figura 21. Artesanos que conocen sobre apoyos de gobierno. Fuente: Elaboración propia con datos obtenidos de aplicación de encuesta.

De los artesanos que conocen o han escuchado sobre los apoyos económicos que otorga el gobierno para el desarrollo o fomento de la actividad artesanal el $52 \%$ ha recibido por lo menos una vez un apoyo de éstos, mientras que el $48 \%$ no han recibido ningún apoyo de gobierno. 


\section{Artesanos que han recibido algún apoyo económico de gobierno}

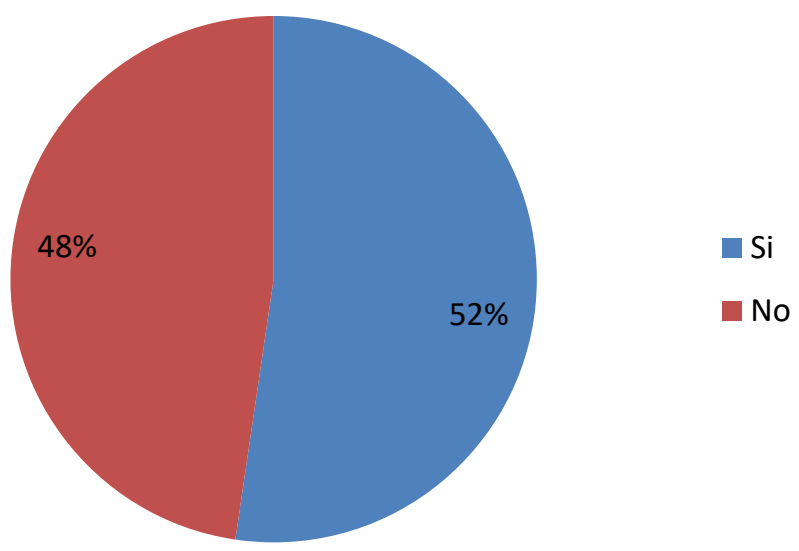

Figura 22. Artesanos que han recibido algún apoyo económico de gobierno. Fuente: Elaboración propia con datos obtenidos de aplicación de encuesta.

De los artesanos que conocen o han escuchado sobre los apoyos económicos que otorga el gobierno para el desarrollo de la actividad artesanal, pero que no han recibido ninguno, el $22 \%$ comentó que no ha recibido apoyo porque solo ha escuchado sobre ellos y desconoce cuáles son los lineamientos para obtenerlos, el $7 \%$ argumento que no ha recibido apoyo de gobierno por no contar con RFC, 51\% no han recibido apoyo por que no cuentan con todos los requisitos solicitados, y el $20 \%$ contestó con otro, siendo los principales argumentos a esta respuesta, que los apoyos solo son otorgados a unos cuantos, no tienen las posibilidades todos los artesanos, o se les otorgan solo a los artesanos que tienen alguna relación con alguna persona involucrada en la entrega de estos apoyos. Ver Figura 23. 


\title{
Razones por la que los artesanos no han recibido apoyo de gobierno
}

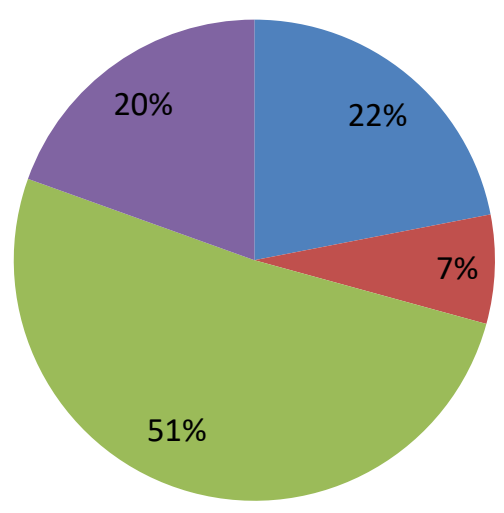

\author{
No conozco sobre \\ los apoyos \\ económicos que \\ otorga gobierno \\ No cuento con RFC \\ No cuento con los \\ requisitos \\ solicitados
}

Otro

Figura 23. Razones por la que los artesanos no han recibido apoyo de gobierno. Fuente: Elaboración propia con datos obtenidos de aplicación de encuesta.

\section{CONCLUSIONES}

La actividad artesanal es una de las muestras más representativas de la diversidad cultural en Oaxaca, se trata de una actividad generacional, es decir, se enseña y va pasando de generación en generación, por lo que actualmente la mayor parte de la población que se dedica a elaborar artesanías es una población adulta con edad de 41 años en adelante, la precarización que conlleva realizar esta actividad está provocando que las nuevas generaciones no quieran dedicarse a ella.

Actualmente se torna más difícil tener acceso a información certera sobre el número de personas que se dedican a la actividad artesanal, nivel de ingresos, educación, etc., por cuestiones de formalidades, es decir es inexacta la información que se obtiene en el INEGI, con respecto a las características socioeconómicas de los artesanos, pues derivado de la globalización, y de la firma del Tratado que firmó México con Estados Unidos y Canadá, en el que se comparte información sobre las actividades económicas de cada país, se hizo necesario el homologar la actividad artesanal dentro de las actividades manufactureras, y aun cuando si se trata de producción de artículos, en este caso artesanales, las condiciones que se tiene en una empresa manufacturera a las condiciones en las que se encuentra un artesano son completamente incomparables.

Existen apoyos económicos en ocho vertientes que el Gobierno Federal otorga a los artesanos, a través del organismo que creó para el Fomento y desarrollo de la actividad 
artesanal, es decir a través del Fondo Nacional de Fomento a las Artesanías, para poder tener acceso a estos apoyos, es indispensable que los artesanos cuenten con RFC, sin embargo, sistémicamente no se cuenta con un programa de acercamiento integral a las comunidades de artesanos.

Actualmente el único régimen de tributación que cuenta con algunos beneficios para los artesanos es el Régimen de Incorporación Fiscal, debido a que da la facilidad de incorporarse al RFC, emitir facturas y pagar impuestos a través de los adquirentes de las artesanías, sin embargo bajo este esquema el margen de utilidad de los artesanos disminuye al tener una retención del 5\% de ISR y del 16\% de IVA, es decir retienen sobre el valor de la artesanía un total del $21 \%$, además la duración de este régimen es de 10 años, lo que pondría en una inequidad a los artesanos para pagar impuestos en comparación a las personas que se encuentran en el régimen de actividades empresariales y profesionales, pues estas personas tienen un nivel socioeconómico más elevado al de los artesanos.

De la forma en que se encuentra los actuales programas de incorporación fiscal, apoyo, capacitación, educación (la cual en teoría es obligatoria) el ser artesano equivale a estar condicionado a ser pobre.

Se considera que dentro de los pendientes como país y sociedad es necesario:

- Disminuir la informalidad, a través de la incorporación al sistema tributario.

- Hacer llegar preparación, capacitación y consultoría a las comunidades más marginadas.

- $\quad$ Reducir las cargas regulatorias sobre las empresas.

- $\quad$ Generar acceso al financiamiento a través de mecanismos adicionales y descentralizados de garantías crediticias.

- Promover bancos comunitarios, sobre todo en las zonas más marginadas.

- Fomentar el emprendimiento a través de: aceleradoras, acceso a información, tecnología y programas de apoyo.

- Impulsar el crecimiento mediante acciones concretas y focalizadas.

- Aumentar el número de empresas micro, pequeñas y medianas, mediante la aplicación de los programas de desarrollo.

- Estimular a las Pymes innovadoras y nuevas empresas mediante 
programas de desarrollo de proveedores y mercados dentro y fuera del país.

- $\quad$ Fortalecer el factor competitivo de los artesanos a través de apoyo integral y permanente a partir de criterios de desempeño.

Finalmente, se tiene la certeza que al contar en México con programas de apoyo que además de incorporar al artesano a la formalidad estimulen, sistémicamente, las facilidades para comercializar sus productos dentro y fuera del país, se tendría un crecimiento económico considerable en la región además de que aumentaría la tributación. Con esto se considera comprobada la hipótesis planteada.

\section{REFERENCIAS}

Alcaraz, R. (2013) El emprendedor de éxito. México: McGrawHill.

Baquero, J. (1950). Trabajador Olvidado del Siglo XX: El Artesano. Miami: Center for Latin American Studies at the University of Miami.

Etienne, J. (2009). Háblame de la Artesanía. París, Francia: UNESCO.

Instituto Nacional de Estadística y Geografía (INEGI). (2010). Anuario Estadistico Oaxaca. Obtenido de Sistema para la consulta del anuario estadístico de Oaxaca 2010: http://www.inegi.org.mx/est/contenidos/espanol/sistemas/aee10/info/oax/mapas.pdf

Instituto Nacional de Estadística y Geografía (INEGI). (2014). Censos Económicos. Obtenido de Sistema Automatizado de Información Censal: http://www.beta.inegi.org.mx/app/saic/default.aspx

UNESCO (24 de Octubre de 2007). "Construir la confianza - La artesanía, elemento del desarrollo", UNESCO.ORG. Recuperado el 25 de Junio de 2018: http://portal.unesco.org/culture/es/ev.php-

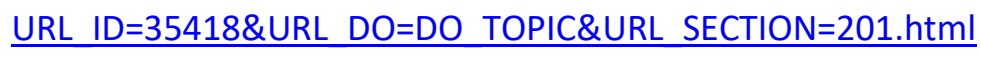




\section{ANEXOS}

Anexo 1. Cuestionario aplicado a los artesanos del estado de Oaxaca, región Valles Centrales.

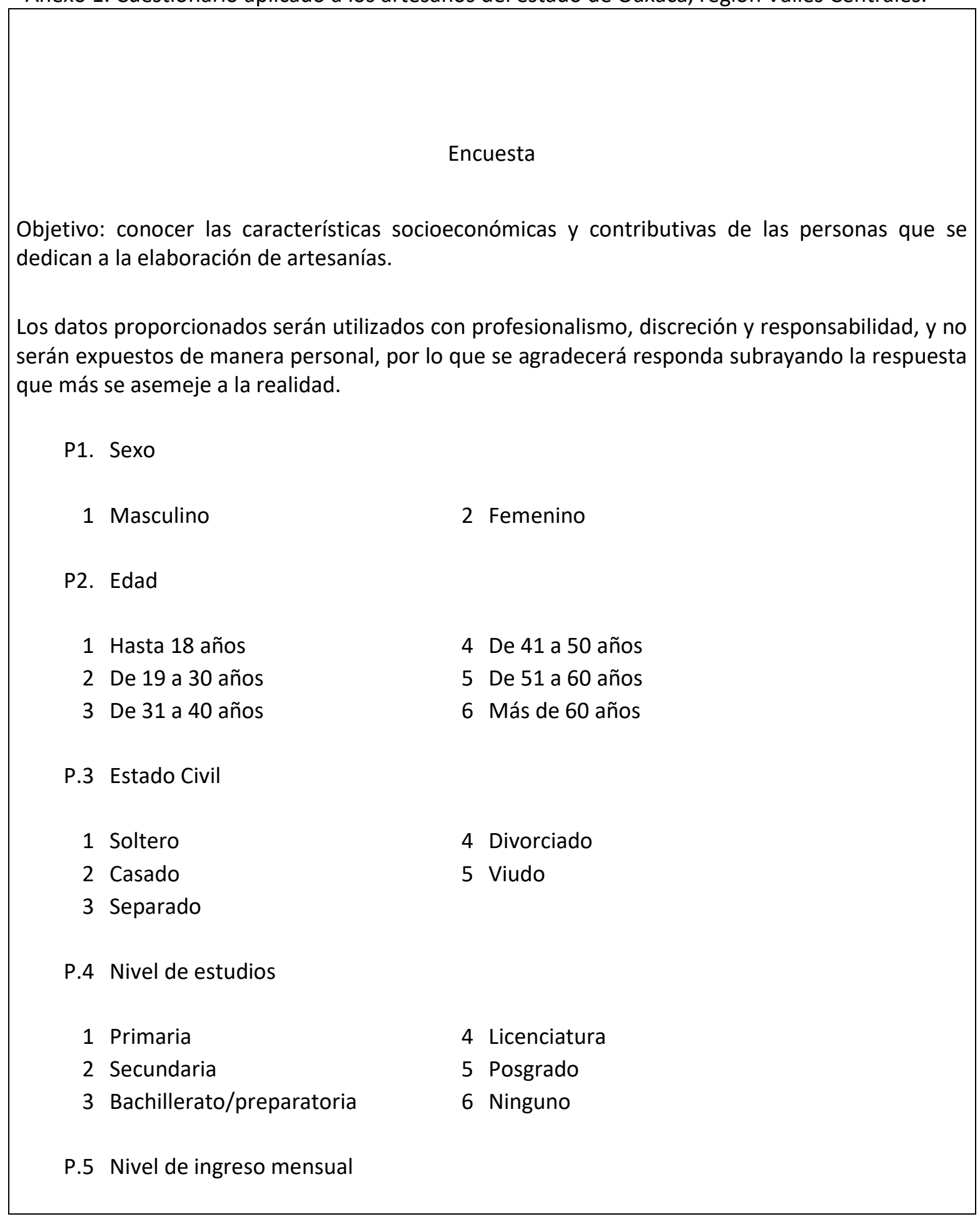


1 Hasta $\$ 2,191.20$

2 De $\$ 2,191.21$ a $\$ 6573.60$

3 De $\$ 6573.61$ a $\$ 10,956.00$
4 De $\$ 10,956.00$ a $\$ 15,338.40$

5 De $\$ 15,338.41$ a $\$ 19,720.80$

6 Más de $\$ 19,720.80$

P.6 Fuente de ingreso

(Si la respuesta es 2 o 4 favor de pasar a la pregunta 12)

1 Elaboración y venta de artesanías

2 Compra y venta de artesanías

3 Elaboración, venta de artesanías y otro no afecto a las artesanías

4 Compra, venta de artesanías y otro no afecto a las artesanías

P.7 ¿Cuenta con personal que le ayuda a la elaboración de sus productos?

(Si la respuesta es No favor de
$1 \mathrm{Si}$
2 No
pasar a la pregunta 10)

P.8 Las personas que le ayudan en la elaboración de los productos son:
1 Familiares
2 Trabajadores (no familiares)

P.9 Retribuye económicamente a las personas que le apoyan en la elaboración de los productos:
$1 \mathrm{Si}$
2 No

P.10 La materia prima para la elaboración de sus productos la obtiene de:

1 Proveedores

2 Recursos Naturales

3 Otro (especifique)

P.11 ¿Qué tiempo tarda en elaborar el producto?

1 Hasta 5 días

2 De 6 a 10 días

3 De 11 a 15 días
4 De 16 a 20 días

5 Más de 21 días

¿Pertenece a algún grupo de

P.12 artesanos? 
P.13 ¿Se encuentra inscrito en el Registro Federal de Contribuyentes (RFC), SAT o Hacienda?

$1 \mathrm{Si} \quad 2$ No

(Si la respuesta es Si favor de pasar a la pregunta 15)

P.14 ¿Por qué no está inscrito en el RFC?

1 Por falta de información

2 Por falta de interés

3 Otro (especifique)

(Favor de pasar a pregunta 21)

¿Por qué razón se dio de alta en el

P.15 RFC?

1 Para poder emitir facturas

2 Porque fue requisito para tener acceso a apoyos económicos

3 Porque fue exigido por el SAT, Hacienda o Finanzas

4 Otro (especifique)

P.16 ¿Con que actividad está inscrito en el RFC?

1 Régimen de incorporación fiscal

Otro

2 Actividad empresarial

3 (especifique)

P.17 ¿Conoce cuáles son sus obligaciones fiscales?

$1 \mathrm{Si}$

2 No

P.18 ¿Cumple con sus obligaciones fiscales como lo es el pago de impuestos?
$1 \mathrm{Si}$
2 No

P.19 ¿Qué impuestos paga? (se puede seleccionar más de 1) 
1 ISR

2 IVA

3 IMSS
Otro

4 (especifique)

P.20 ¿ ¿Por qué no paga impuestos?

1 No me interesa

2 Falta de conocimiento

3 Falta de recurso
Otro

4 (especifique)

P.21 Si existiera un Régimen de tributación especial para artesanos ¿Se daría de alta en el RFC bajo este nuevo régimen?
$1 \mathrm{Si}$
2 No

P.22 ¿Conoce los apoyos económicos que otorga gobierno a los artesanos?

$1 \mathrm{Si}$

(si la respuesta

es $\mathrm{Si}$

fin de la

encuesta)
2 No

(si la respuesta es No fin de la encuesta)

P.23 ¿Ha tenido acceso a algún apoyo otorgado por gobierno?

P.24 ¿Por qué no ha tenido acceso a algún apoyo otorgado por gobierno?

1 No conozco sobre los apoyos económicos que otorga gobierno No cuento

2 con RFC

3 No cuento con los requisitos solicitados

Otro

4 (especifique)

¡Gracias por su tiempo! 
Anexo 2. Guión de entrevista personal

Entrevista personal

Nombre del entrevistado(a):

Nombre del negocio:

Actividad artesanal:

1. ¿Cuántos años lleva desarrollando esta actividad?

2. ¿Cómo aprendió a desarrollar esta actividad?

3. ¿Cuánto tiempo le tomó aprender todo lo necesario para desarrollar por cuenta propia esta actividad?

4. ¿Considera que el desarrollo de la actividad artesanal ha disminuido al pasar de los años? ¿Por qué razón?

5. ¿Considera que la actividad artesanal se encuentra directamente relacionada con la preservación de la cultura mexicana y su diversidad? ¿Por qué razón?

6. ¿Cómo considera el trato dado por parte de gobierno a los artesanos? ¿Por qué razón?

7. ¿Se encuentra inscrito o afiliado a alguna asociación o institución que agrupe a artesanos? ¿Cuál?

8. ¿Qué dependencias de gobierno conoce que apoyen a los artesanos?

9. ¿Ha recibido algún apoyo económico por parte de gobierno para el desarrollo de la actividad artesanal que realiza?

10. ¿Se encuentra inscrito en el Registro Federal de Contribuyentes? ¿Por qué razón?

11. ¿Conoce algún régimen fiscal que beneficie al desarrollo de la actividad artesanal? ¿Cuál?

12. ¿Si existiera un régimen de tributación especial para artesanos, se daría de alta en el RFC bajo este régimen?

13. ¿Qué podría sugerir al gobierno, para que los artesanos cumplieran con las obligaciones fiscales? 
14. ¿Cuánto tiempo tarda en elaborar un producto?

15. ¿Los recursos que utiliza para elaborar las artesanías de donde los obtiene?

16. ¿Cuál es el precio de venta de una de sus artesanías?

17. ¿Tienen temporadas altas? 